\title{
EINSIEIN'S PIILOOSOPIIY OF SCILNC:E
}

\author{
Bruce Holmet
}

Consider a beginning scientist who plans to perform a series of experiments. Before he can begill he must have a philosophical basis from which he will plan his activity. For instance, why does he perform experiments in the first place? could he not achieve results in extending knowledge by puse thought, without performing experjments? If he does decicle on carying out experiments, then he must be assured that he actually measules qualities which have meaning. once he has collected the data and combined it with all the previously collected data, call he hope to make order out of the arlay of empirical data, and how call his theorizing coleate this order? ndmitiedly, all scientists have at least vaguely answered these basic questions, but one must note that the scientissts of great intellectual stature have carefully considered thesse and similar issues as they formed their individual scientific philosiophies.

of particulal interest, not only because of his contributions to science, but also because he spoke in great detail about his own philosoplyy, is nlbert Einstein. Mis paper will cover only thee majn aspects of linstoin's philosophy of science: the llatule of the universe, the tedationship belween sensory experience and our concept of teality, and the construction of scientific theory. I'o rinsitein all understanding of the physical miverse starts with empirical data, and this data can be cortelated and understood, for the universe has an implicit mathematical stincture. Furthermose, the formation of our perception of reality is a lwo-step process: first:, the formation of the concept of a bodily object which corresponds to certain repeatedly occurring complexes of sense implession, and second, the attribution of significance to this concept. 
Comprehenrion of sense experiences, and thus realjty, is then possible through the ordering of our concepts of bodily ohjects. Finally. Einstein preceived the construction of scientific theory as an interplay between reason and experience. Basic postulates, concejved entirely by free invention of the mind, are the basis of a theory, and all concepts and relations among concepts which are directly related to our sensoty experience call be derived from this basis. since the scope of each point cannot be appreciated without further discussion, I shall examine all these point:r in more detail.

If one is to understand the nature of the physical universe, then according to Einstein one must begin with senroty experiences. IJe believed that "conclusions obtained by purely rational processes ate. so far as Reality is concerned, entirely empty." 1 "This conviction does not rest on the supposition that anyone has actually proved the impossibility of gaining knowlerge of reality by means of pure speculation, but rather upon the fact that the empirical . . procedure nlone has shown its capacity to be the source of knowledge. "2 Yet this is not to say that reason has no part in the acquisition of knowledge, for one must also avoid the other extreme: "naive realism, according to which things 'are' as they are perceived by us through our sonses." ? Thus, as the reader will Jater clearly see, inderstanding of the universe comes shout through the interaction between reason and experience.

reperience alone can lead to a knowledge of Nature's structure; moreover, its very structure is mathematical. Einstein often spoke of the harmony of the universe. He was motivated to search for this harmony by a feeling for "the sublimily and marvelous older which reveal. themselves hoth in nature and in the world of thought." He claimed that one can express mathematically the harmony and order of the iniverse. Ehysjes has shown that scientific concepts and propositions lend themselves to mathematical formulition, and furthermole: "Our expericnce lin sciencel un to date justifies us jn reeling sure that in Nature is actualized the ideal of mathematical simplicity."ri Einstein used the ceneral Theory of Relalivity to illustate the point of mathematical simplicity: 
Ihe physical world is represented as a four-dimensional contisuum. If in this I adopt a Riemannian metric, and look for the simplest I aws which such a melric: can satisfy, I arijue at the relativistic gravitationtheory of empty space. If I adopt in this space a vector-field,. . and if 1 look for the simplest laws which such a field can satisfy. 1 arrive at the Maxwell equations for free space. 6

Ihus the laws of Nature ale fundamentally simple elements of a mathenatical structure; however, the mathematical structure itself may be quile abstract.

Although Nature seens to present us with an overwhelming array of sensory experience, one can, nevertheless, uncover the mathematical structure of reality. Knowledge of this mathematical structure is synonymous with the understanding of Nature. It is conceivable that many mathematical sturctures could be found to explain Nature, but Einstein believed that only one of the structures would be "best" (the criteria for "best" will be discussed Jater). Therefore, Nature can be understood uniquely; in other words, a unique mathematical structure which fits Nature exists and can be found.

Another characteristic of the physical universe is that a "complete" description of reality is possible. By "complete" Einstein referred to the requirement that "every element: of the physical reality must have a counterpart in the physical theory." 7 "Thus no part of physical reality can be excluded from the matheinatical structuse of the universe if the stucture is to be complete. Equivalent to this idea of completeness is the deterministic view in which a direct representation of physical leality in space and time is possible; that is, the universe is exactily engineered. Yet, contrary to the concept of an exactly engineered universe is guantum theory, which incorporates a probability element into its mathenatical structure. Einstein strongly objected to this element of probability, claiming that the presence of probability in guantum theory "is solely to be ascribed to the fact that [quantum theory] operates with an incomplete description of physical systems." 8 Some points of quantum theory, however, were already well established--in particular, the Heisenberg uncertainty ptinciple--so Einstiejn made the concession that no 
"Future lempiricall knowledge can compel physics again to relinguish our present statistical lineoretical founclation in favor of a deterministic one... ." The lleisenberg uncertainty principle excludes the possihility of obtaining empirical data that would directly contradict quantum theory. Yet, Einstein retained his faith in a deterministic view of Nature, For he felt that eventually a deterministir: mathematical formulation could be found which would explain the empirical data at a deeper level and would not contain elements of probability. Empirical data, however, would not lead to this deterministic theory: onjy the intuition and ingenuity of a theorist could lead to its discovery.

After considering Finstein's view of the nature of the universe, some possible answers arise for our beginning srientist's questions. According to Einstein the scientist must perform experiments because up to the present time pure thought alone has not yielded useful information about the physical world. The scientist has the assurance that Nature has an implicit mathematical structure which can be described completely and which can be uncovered. Yet, in the previous discussion ideas were introduced, such as "reality" and "concepts," that need fulther definition and discussion. The next sertion, therefore, wi.11 explore the relationship between sensory experience and our concept of reality.

1r. a scientist is concerned about whether or not the qualities that he measures have meaning, then he must first consider the processes involved in the formation of reality from sensory experience. As E.instein stal.ed, "The whole of science is nothing more than a refinement of everyday lininking," and he contimued: "['the physicist] cannot proceed without: considering critically. . . the problem of analyzing the mature of everyday thinking." 10 First of all. "we shall. take the existence of sense experjences as given, lhat is to say as psychic experiencs of lal special kind."Ii After assuming the actuality of sensory experiences one now finds that the formation of a "real external world" involves two steps: the formation of the concept of a bodiJy object. and the attribution of sicnificance in this concept.

Einstein describes the first of these steps in the following manner: 
out of the multitude of our sense experiences we take, mentally and arbitrarily, certain repeatedly occurring complexes of sense impression . . and we attribute to them . . the meaning of the bodily object. considered logically this concept is not identical with the totality of sense impressions referced to; but it is an arbitrary creation of the human (or animal) mind. On the other hand, the concept owes its meaning and its justification exclusively to. the totality of the sense inpressions which we associate with it. 12

Thus, the process involves the selection of certain sense impiessions which one groups together and then their association with the concept of a bodily object. When a certain set of sense impressions turns up in many menory-pictures, then it becomes an ordering element for a series of such menory-pjctures in that it connects memoties which in themselves are unconnected. "Such an element becomes an instrument, a concept." 13 Yet, a concept formed in one's mind is not the sum of all the particular sensory experiences in the memory that coincide with the concept, but it: is something independent--a free creation of the human mind. 'l'hus, a concept is somewhat removed from the sensory experiences to which it pertains. This gap between data of sense and concepts of thought is not easily noticed since we tend to combine certain concepts with certain sensory experiences. I4 Actually, "the connection of the elementary concepts of everyday thinking with conplexes of sense experiences can only be comprehended intuilively and it is mnadaptable to scientifically logical fixation." is

After this concept of a hodily object is formed one attributes significance to it. Einstein explains this second step in the setting up of a "real external world" in the following statement:

attribite to this concept of the bodily object a significance, which is to a higu degree independent of the sense impression which originally gives rise to it. I'his is what we mean when we attribute to the bodily object "a real 
existence." The justification of such a setting rests exclusively on that fact that, by means of such concepts and mental relations between them, we are able to orient. ourselves in the labyrinth of sense jmpressions. These notions and relations, a) though free statements of our thoughts, appear to us as stronger and more unalterable than the individual sense experience. itself... On the other hand, these concepts and relations, and indeed the setting of real objects and, generally speaking, the existence of "the real world," have justification only insofar as they are connected with sense impressions bctween which they form a mental connection.

"The real world," and therefore our concept of reality, is just a result of the significance that one attributes to the concepts of objects. These concepts are free statements of our thoughts, yet one employs a pacticular set of concepts because that set is useful.

The essential criterion for the use fulness of a set of concepts is that the world of sense experience becomes comprehensible through the application of that set of concepts. Comprehensibility of the world proceeds from the production of some sort of order among sense impressions. Jt is the creation of general. concrepts and relations between these concepts that produces the desired order, and thus comprehensibility 17 The origin of concepts thus lies in rree invention of the mind, while the function and justification of these concepts resides in the ordering of experience. Now, if one considers physical reality. the formation of reality becomes the conmitment to a statement of a set of rules, rules guiding the creation of general concepts and relations between the concepts. success in hringing about order is the sole determining factior in the selection of these rules. While the tilles themselves are arbitrary, their rigidity makes the setting up of a real extermal world possible. "However, the fixation lor the rules) wijl never be rinal. It wijl have validity only for a special field of application (i.e., there are no final categories in the sense of Kant)." 18 Any set of rules is allowable as long as it leads to the desired resull. 
Recapitulating the processes at: work in the formation of reality from sense experience, one finds that our concept of "the real world" is determined by concepts which arange the array of sensory experience. The general concepts, which are free creations of the mind, and relations between them must satisfy the condition that they create order in our perception of Nature, and thus make the world comprehensible. Now, how does this explanation of reality help our beginning scientist, who needs assurance that he actually measures qualities that have meaning? One thing is clear: the qualities that he measures must correspond to the specific set of concepts which he uses to set up reality. A problem, though, seems to present itself. for what if our scientist picked a new set of concepts for defining reality--how will this affect the theory based on his perception of the experimental results? Probable answers to this question will not be apparent until we explore the processes behind the creation of a scientific theory.

\section{11}

Up to this point I have outlined the philosophical considerations behind the collection of experimental data, but now consider what Einstein said about the formation of a theory from this data: "The essential thing is the aim to represent the multitude of concepts . . close to experience, as theorems, logically deduced and belonging to a basis. . of fundamental concepts and fundamental relations which themselves can be chosen freely. . . ."l? More specifically, one begins with the general concepts (from now on called "primary concepts") which are directly and intuitively connected with sensory experiences, then "one invents a system with fewerl concepts and relations, a system retaining the primary concepts and relations of the 'first layer' as logically derived concepts and relations." 20 "This new layer has a greater logical unity than the first layer, because it contains fewer concepts and relations. "Further striving for logical unity brings us to a tertiary system.. . . I'hus the story goes on until we have arrived at a system of the greatest conceivable mity. . . "2l The importance of this last system, which contains the most basic concepts and laws, cannot be overstated. Einstein once explained:

"I'he basic concepts and laws which are not logically further reducible constitute the indispensable and not 
rationally deducible part of the theory. It can scarcely be denied that the supreme goal of all theory is to make the irreducible basic elements as simple and as few as possible without having to surrender the adequate representation of a single datum of experience." 22

Thus, a theory can be judged by two criteria, one empirical and the other rational. First of ali, a theory must not contradict empirical [acts, and it must apply to and explain the largest realm of experience possible. Moreover, a theory should make the universe as "rational" as possible. Equivalent to this rationality is the "logical simplicj.ty" of the most basic concepts. The simpler theory is the theory which is based on the smaller number of logically independent fundamental concepts. The logically simpler theory. however, is mathematically more abstract.

The structure of a theory is now evident; futhermore, the dynamic process that creates such a structure is the interplay between reason and experience. Reason provides the structure, whereas experience is the sole judge of the theory's validity. The structure of the theory is not derived by logical induction from empirical data, for the most basic concepts, which possess the greates logical unity, cannot be deduced logically from the primary concepts. but rather the most basic concepts are free inventions of the human mind whose only justification is the correspondence of the concepts logically derived from them with the data of experience. To illustrate the arbitrary nature of the basic concepts consider Newtonian physics and the General Theory of Relativity. each of which in its consequences leads to a large measure of agreement with experience, but each of which uses basic principles very far removed from those of the other. 25

Now that one realizes that the basic concepts of a theory are free inventions of the human mind, has one any right to hope that he shall rind the correct way to an ultimate theory? For,

one might suppose that these were any number of. possible systems of theorelical physics all with an equal. amount to be sajd for them; and this opinion is no doubt correct, theoretically. But 
evolution has shown that at any given moment, out of all conceivable constructions, a single one has always proved itself absolutely superior to all the rest. Nobody who has teally gone deeply into the matter will deny that in practice the world of phenomena uniquely determines the theoretical system, in spite of the fact that there is no jogical bridge between phenomęna and their theoretical principles.

Einstein felt strongly that there is the correct "path" to an ultimate theory and that it is in one's power to find that path. Yet Einstein's philosophy will not allow the ultimate theory to be a "perfect theory" which will keep its form and construction for eternity. because the form and construction of the theory is dependent upon the particular set of primary concepts that one chooses to order sense experience. If the primary concepts are changed, thell the forn and structure of the "perfect theory" must necessarily change. The correct "path" to the ultimate theory may be found, however, for a given set of primary concepts. In this case the most basic concepts may cliange in form again and again but will converge toward a final set of fundamental principles which will be the basis of an ultimate theory.

The idea of changing our set of primary concepts used for ordering reality brings up the problem that our beginning scientist faced: how will this change in concepts affect the theories based on his perception of the experimenta] results? Since the primary concepts must agree with the logicgal consequences of the theory's basic concepts, â change in the primary concepts can conceivably cause a cliange in the fortn of these basic concepts. This change in the basic concepts is most likely comnected with the fact that a set of prinaly concepts does not exactly represent the entirety of sensory experience. Thus:

"It may be argued that the arbitiary
selection of complexes of sense-
experiences represents a sort of
interference with the given totality
of sense-impressions. We should be
conscious that such interference,
implied in the formation of primary
concepls, is of still greater
significance when secondary concepts 
and the laws of their interrelations

Moreover, a change in the set of primary concepts used for ordering reality could be the key for achieving a breakthrough in the striving for greater logical unity at the level of basic concepts, for if one finds that all attempts to achieve greater logical unity among the basic concepts fail, then one might attempt to pick a new set of primary concepts for which one might find a group of basic concepts with greater logical unity than those associated with the old set of primary concepts.

In the fear that our beginning scientist might become lost in the above speculations, perhaps it would be best to summarize the construction of scientific theory:

Physics constitutes a logical system of thought which is in a state of evolution, and whose basis cannot be obtained through distillation by any inductive method from the experiences lived through, but which can only he attained by free invention. The justification (truth content) of the system rests in the proof of usefulness of the resulting theorems on the basis of sense experiencs, where the relations of the latter to the former can only be compreliended intuitively. Evolution is going on in the djrection of increasing simplicity of the logical basis. In order further to approach this goal, we must make up our mind to accept the fact that the logical. basis departs more and mote from the facts of experience, and that the path of our thought from the fundamental basis to these resulting theorems, which correlate with sense experiences, becomes contimalily harder and longer. 
NO'IES

1Albert Einstein, on The Method of lheoretical Physics (New York: oxford University Press, $193 \overline{3}$ ), p. 8.

2 Albert Einstein, The Philosopliy of Bertrand Russell, The Libary of I.iving phitosophers, vol. V. ed. Paul A. Schilpp, rpt. in Ideas and Opinions, Albert Einstein (New York: Crown Pubíshers, Inc., 1963), p. 21 .

3 Ibid. , p. 20.

4 Albert Einstein, "Religion and Scjence," New York Iines Magazine, Nov. 9, 1930, rpt. in ldeas and opinions. p. 38 .

${ }^{5}$ Einstein, Method, pp. 14-15.

6instein, Method, pp. 15-16.

7 Albert Einstein, "can Quantum-Mechanical Description of Physical Reality Be Considered Complete?," physical Review, 47 (May 15, 1935), p. 777.

${ }^{8}$ Albert Einstein, "Remarks to the Essays Appearing in This collective Volume," in Albert Einstein: Philosopher-Scientist, The Libraiy of fiving Fitilosophers, vol. Vİl, ed. Paul A. Schil.pp (Evanstion: The Library of hiving Philosophers, Inc., 1949), p. 666 .

${ }^{9}$ Albert Einstein, "Considerations concerning the Fundaments of 'rheoretical Physics," Science, 91 (May 24, 1940), p. 491.

10) Albert Finstein, "Physics and Reality," Journal of the Eranklin Institute, 221 (Match 1936). p. $\overline{3} \overline{49}$. 
11 Finstein, J. Franklin Inst., p. 350.

12 Finstein, J. Franklin Inst., p. 350.

13 Albert Einstein. "nutobiographical Notes," in Albert Einstein: Fhilosopher-scientist, p. 7 .

14 victor: F. Lenzen, "Einstein's 'lheory of knowledge," in nlbert Einstein: Philosopher-Scientist, p. 360 .

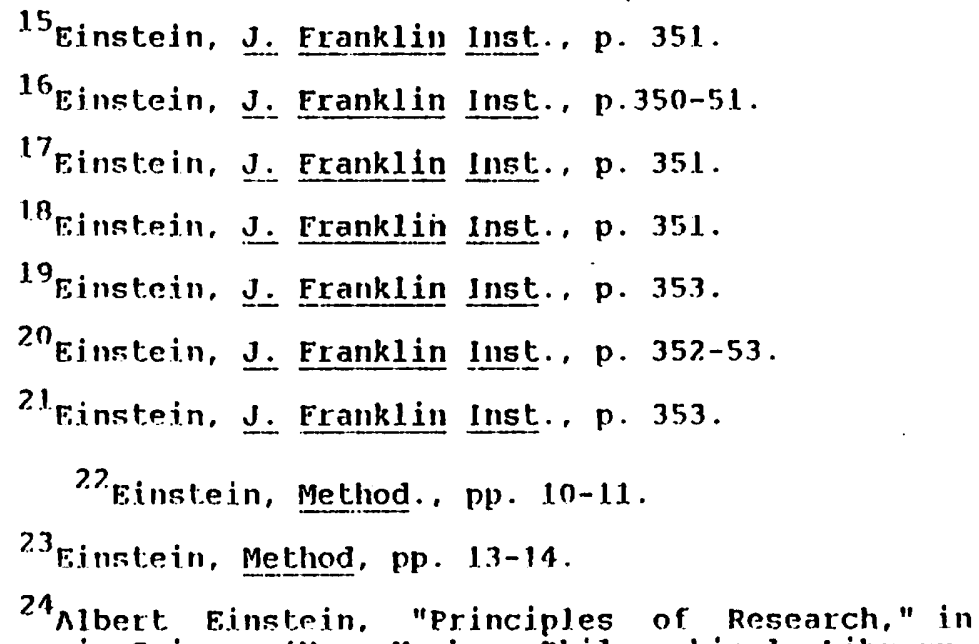
Essays in Science (New York: Philosophical Library.

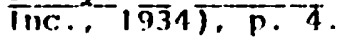

${ }^{25}$ See Philipp Frank, "Finstein's Philosophy of Science," Reviews of Modern Flhysics. 21 (J11). 1949). p. 354 .

26I1se Rosenthal-Schmeider, "Presuppositions and nit.icipations in Finstein's Physics," in Albert Einstein: Philosopher-Scientist. p. 133.

${ }^{27}$ Einstiein. I. Fanklin Inst., p. 381 . 